\title{
Adiponectin through its biphasic serum level is a useful biomarker during transition from diastolic dysfunction to systolic dysfunction - an experimental study
}

Mingqiang $\mathrm{Fu}^{1 \dagger}$, Jingmin $\mathrm{Zhou}^{1+}$, Juying Qian ${ }^{1 \dagger}$, Xuejuan Jin ${ }^{1}$, Hongmin $\mathrm{Zhu}^{1}$, Chunlin Zhong ${ }^{1}$, Michael Fu${ }^{2}$, Yunzeng Zou ${ }^{1,3^{*}}$ and Junbo Ge ${ }^{1,3^{*}}$

\begin{abstract}
Background: Adiponectin is reported to relate with cardiovascular diseases, we sought to examine whether adiponectin is associated with disease progression of heart failure from hypertension in rats in comparison with other known biomarkers and echocardiographic parameters. Spontaneously hypertensive rats (SHR, $n=35)$, aged 1 month, were used and followed up to 18 months. High frequency echocardiography was performed both at baseline and every 3 months thereafter. Moreover, serum levels of N-terminal pro-natriuretic peptide (NT-proBNP) and interleukin-6 (IL-6) as well as serum level and tissue expression of adiponectin were determined at the same time as echocardiography.
\end{abstract}

Results: The results clearly demonstrated time-dependent progression of hypertension and heart dysfunction as evidenced by gradually increased left ventricular mass index, NT-proBNP, IL-6 as well as gradually decreased cardiac function as assessed by echocardiography. Meanwhile, tissue and serum adiponectin decreased from 3 months and reached plateau until 12 months in parallel with decreasing of cardiac diastolic function. Thereafter, adiponectin levels increased prior to occurrence of systolic dysfunction. Adiponectin concentration is inversely related with NT-proBNP, IL-6 and E/EI (correlation coefficient $(r)=-0.756$ for NT-proBNP, $p<0.001,-0.635$ for IL-6, $p=0.002$, and -0.626 for $E / E$, $p=0.002$, respectively) while positively correlated with $E / A$ and $E / / A$ / ( $r=0.683$ for $E / A, p=0.001$, 0.671 for $E / / A$ I, $P=0.001$, respectively). No difference for adiponectin distribution among visceral adipose tissues was found.

Conclusion: Adiponectin through its biphasic serum level is a useful biomarker during transition from diastolic dysfunction to systolic dysfunction.

Keywords: Hypertension, Diastolic function, Systolic function, Adiponectin, Biomarker

\section{Introduction}

Adipose tissue has been long considered to be an energystorage compartment before discovery of the various adipocytokines, such as adiponectin, leptin, plasminogen activator inhibitor type 1 (PAI-1), interleukin(IL)-1ß, IL-8, IL-10, and so on $[1,2]$. All these adipocytokines exert

\footnotetext{
* Correspondence: zou.yunzeng@zs-hospital.sh.cn; jbge@zs-hospital.sh.cn ${ }^{\dagger}$ Equal contributors

${ }^{1}$ Shanghai Institute of Cardiovascular Diseases, Department of Cardiology, Zhongshan Hospital, Fudan University, Shanghai, China

${ }^{3}$ Institutes of Biomedical Sciences, Fudan University, Shanghai, China Full list of author information is available at the end of the article
}

multiple biological activities and significantly contribute to the regulation of the body's homeostasis [3,4]. Notable among these is adiponectin, an adipose-tissue-specific plasma protein which is accounting for as much as $0.01 \%$ of total plasma proteins [5].

Adiponectin, also referred to as Acrp30/AdipoQ/apM1/ GBP28, belongs to the collectin family [6] and contains four structural domains based on its primary sequence: an $\mathrm{N}$-terminal signal peptide, a short hyper-variable region, a collagen domain, and a C-terminal globular domain homologous to C1q [7]. Basic researches and clinical studies 
have demonstrated that it not only exhibited anti-diabetic, anti-atherogenic and anti-inflammatory properties [8-10] but also had important protective effects at cardiovascular level [11]. However, the role of adiponectin in the development of cardiac diseases remains less clear than it does for metabolic disorders. Initial evidence from clinical studies showed that exposure to angiotensin II receptor blockers increased circulating levels of adiponectin. Moreover, the induction of hypertension with angiotensin II injection leads to a decrease in plasma adiponectin concentration concomitant with blood pressure elevation [12]. The association between adiponectin and hypertension is also evident in clinical studies by showing that hypoadiponectinemia is a risk factor for hypertension independent of insulin resistance and diabetes $[13,14]$. However, till to now, few studies address the time-frame changes of adiponectin during transition from hypertension to onset of cardiac dysfunction and heart failure. Therefore, our hypothesis is that adiponectin may serve as a useful biomarker for transition from left ventricular hypertrophy to cardiac dysfunction and heart failure. In this study, we examined whether serum and tissue adiponectin levels are associated with onset of heart failure from hypertension through left ventricular hypertrophy in rats in comparison with other known biomarkers for heart function and inflammation.

\section{Materials and methods \\ Animals}

Thirty five male spontaneously hypertensive rats (SHR) were purchased from Shanghai Laboratory Animal Center, Chinese Academy Sciences at 2 weeks of age. All rats were maintained in a specific pathogen-free room under conditions of temperature- and humidity- controlled with a 12:12-h light-dark cycle and given standard laboratory chow and tap water ad libitum. The starting age was 4 weeks. All of the animal experiments were performed in compliance with the Guide for the Care and Use of Laboratory Animals published by the US National Institutes of Health (NIH Publication No. 85-23, revised 1996) and was approved by the guidelines for animal research of Zhongshan Hospital, Fudan University.

\section{Experimental protocol}

SHR were weighed, and systolic blood pressure (SBP) and heart rate (HR) were measured by a tail-cuff method (BP98A, Softron, Tokyo, Japan) while conscious at 1, 3, 6, 9, 12, 15 and 18 months of age, respectively. After body weight (BW) and SBP data obtained, transthoracic high frequency echocardiographic studies were conducted. Thereafter the rats were sacrificed at each of the above time points to measure the levels of serum NT-proBNP, IL-6 and adiponectin, as well as the distribution and changes of adiponectin in different visceral adipose tissues.

\section{Echocardiographic studies}

SHR were anesthetized with intraperitoneal injection of $50 \mathrm{mg} / \mathrm{kg}$ ketamine hydrochloride, and an additional 0.1-0.3 ml was given if needed. Rats were allowed to breathe spontaneously during the echocardiographic studies with a mean heart rate at $393 \pm 18 \mathrm{bpm}$.

After being anesthetized, the rats were transferred to a heated platform and precordial region of the rats was shaved and warmed acoustic coupling gel was applied. Subsequently, transthoracic echocardiographic measurements were performed in the supine position with a commercially available echocardiographic system (Vevo770 High Resolution Imaging System, Visual Sonics, Toronto, Canada) using a $17.5 \mathrm{MHz}$ transducer. The transthoracic echocardiographic probe was placed to obtain parasternal long and short-axis cardiac views. From the cardiac long axis, an M-mode trace of the LV was obtained, and heart rate (HR), LV end-diastolic diameter (LVEDD), LV end-systolic diameter (LVESD), LV posterior wall thickness (LVPW) and interventricular septum thickness in diastole (IVS) were measured following the American Society of Echocardiography guidelines [15]. The LV ejection fraction (EF) and fractional shortening (FS) were measured directly from the longaxis image. Mitral inflow was recorded at the tip of the mitral valve from a parasternal long-axis view using Pulsed-Wave Doppler Imaging. We measured maximal velocities of the $E$ and $A$ waves, isovolumic relaxation time (IVRT, defined as the interval between the aortic closure click and the start of mitral flow) and deceleration time of the $\mathrm{E}$ wave (DT, the interval between the peak early diastolic velocity and the point where the steepest deceleration slope was extrapolated to the baseline) [16]. E/A ratio was calculated. Using Tissue Doppler Imaging, both wall movement at the level of the lateral mitral annulus from the parasternal long-axis view and maximal velocity of early $(\mathrm{E} /)$ and late $\left(\mathrm{A}^{\prime}\right)$ diastolic waves were recorded. $E^{\prime} / A^{\prime}$ and $E / E^{\prime}$ were calculated. All measured and calculated indices are presented as the average of three consecutive cardiac cycles. The studies were performed by a trained echocardiographer who was blinded to the protocol. The gained images and data were stored and then downloaded to a magnetooptical disk for offline analysis.

\section{Serological studies}

After echocardiography completed, adequate anaesthesia was achieved by additional intraperitoneal administration of ketamine hydrochloride. An incision was made in the abdomen, blood was sampled from the inferior vena cava and kept at $-80^{\circ} \mathrm{C}$ for subsequent assay of NTproBNP, IL-6 and adiponectin. Commercially available enzyme linked immunosorbent assay (ELISA) kits (ADL Biotechnology, Inc., USA) were used to measure serum 

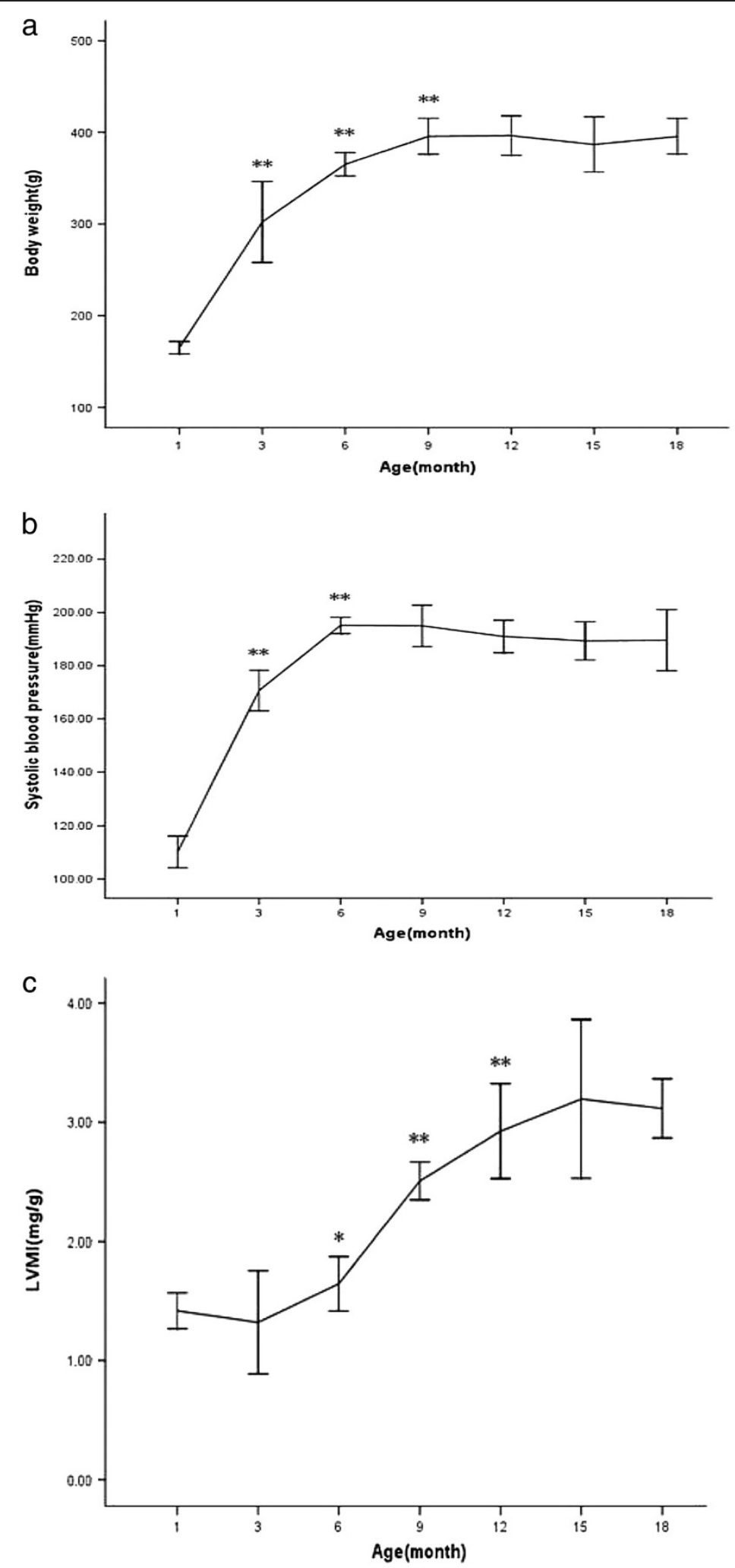

Figure 1 Changes in body weight (a), systolic blood pressure (b) and left ventricular mass index(c) for SHR. * $p<0.05$ vs. previous time point; ${ }^{* *} p<0.01$ vs. previous time point. 
NT-proBNP, IL-6 and adiponectin concentrations respectively according to the manufacturer's instructions. Because the distributions of NT-proBNP and adiponectin were skewed, logarithmically transformed values were used for statistical analysis.

\section{Quantification of adiponectin and IL-6 mRNA expressions} After blood samples obtained, the abdominal incision was prolonged upward to the chest, and pericardial, perinephric and mesenteric adipose tissue samples were harvested from each SHR and quickly stored at $-80^{\circ} \mathrm{C}$ for subsequent tissue study. Meanwhile, the LV was incised, retrieved and washed in $0.9 \% \mathrm{NaCl}$ and then drawn up liquid by filter paper to get weighed for the calculation of left ventricular mass index (LVMI).

Total RNA was prepared by RNA-Trizol extraction (Invitrogen) and treated with DNase I (Takara). cDNA was synthesized using Reverse Transcription System (Promega, Madison, WI, USA) according to the manufacturer's instructions. Quantitative Real-Time PCR (qRT-PCR) analysis was performed on an iCycler system (Bio-Rad, Hercules, CA, USA) using SYBR GREEN I as a doublestranded DNA-specific dye according to the manufacturer's instructions (Applied Biosystems, Foster, CA, USA). Primers were designed as follows: $5^{\prime}$ - CAG GTT GGA TGG CAG GCA TC-3' (sense) and 5'-GTA AGC GGC TTC TCC GGG CT-3' (antisense) for rat adiponectin, 5'-ACT TCA CAA GTC GGA GGC TT-3' (sense) and 5'-AGT GCA TCA TCG CTG TTC AT-3' (antisense) for rodent IL-6, 5' - CAG TGC CAG CCT CGT CTC AT-3' (sense) and $5^{\prime}$-AGG GGC CAT CCA CAG TCT TC-3' (antisense) for rodent GAPDH. All primers were obtained from Sangon Biotech (Shanghai) Co., Ltd. The expression levels of examined transcripts were compared to that of GAPDH and normalized to the mean value of controls.

\section{Western blot analysis}

The adipose tissue samples were homogenized in lysis buffer (Cell Signalling Technology, Inc., USA) with protease inhibitor cocktail (Sigma Chemical Co., St. Louis, MO, USA). Protein content was determined by the BCA method. The same amounts of protein $(50 \mu \mathrm{g})$ were separated with denaturing SDS $10 \%$ polyacrylamide gels. The membranes were immunoblotted with the primary antibodies at a 1:1000 dilution followed by incubation with secondary antibody conjugated with horseradish peroxidase (HRP) at a 1:2000-1:5000 dilution. Bands were visualized using ECL Western Blotting Detection kit (Amersham Pharmacia Biotech, Piscataway, NJ).

\section{Statistical analysis}

All values are expressed as means \pm standard deviation (SD). Group differences were analyzed by analysis of covariance (ANOVA). To compare multiple groups, MannWhitney U-test with Bonferroni correction was used. Bivariate analysis was performed to determine the correlation between plasma adiponectin levels and the other continuous variables. Group differences or correlations with $\mathrm{p}<0.05$ were considered as statistically significant. All analyses were carried out with SPSS16.0 statistical package for Windows (SPSS Inc, Chicago, Illinois).

Table 1 Echocardiographic data of SHR

\begin{tabular}{|c|c|c|c|c|c|c|}
\hline \multirow[b]{2}{*}{ Month(s) } & \multicolumn{4}{|c|}{ Chamber and wall dimensions } & \multicolumn{2}{|c|}{ Systolic function } \\
\hline & $\operatorname{LVEDD}(\mathrm{mm})$ & $\operatorname{LVESD}(\mathrm{mm})$ & IVS(mm) & $\operatorname{LVPW}(\mathrm{mm})$ & $\mathrm{EF}(\%)$ & $\mathrm{FS}(\%)$ \\
\hline 1 & $3.79 \pm 0.29$ & $1.71 \pm 0.09$ & $1.28 \pm 0.18$ & $1.14 \pm 0.08$ & $90.87 \pm 0.95$ & $62.32 \pm 1.05$ \\
\hline 3 & $4.79 \pm 0.22^{* *}$ & $1.89 \pm 0.09$ & $1.60 \pm 0.09^{* *}$ & $1.60 \pm 0.14^{* *}$ & $91.45 \pm 0.54$ & $63.46 \pm 1.69$ \\
\hline 6 & $5.22 \pm 0.42^{* *}$ & $1.95 \pm 0.07$ & $1.79 \pm 0.11^{* *}$ & $2.39 \pm 0.23^{* *}$ & $90.67 \pm 0.65$ & $62.73 \pm 1.29$ \\
\hline 9 & $5.51 \pm 0.38^{* *}$ & $2.60 \pm 0.24^{* *}$ & $1.83 \pm 0.12^{* *}$ & $2.51 \pm 0.20^{* *}$ & $91.15 \pm 0.69$ & $62.89 \pm 1.94$ \\
\hline 12 & $5.61 \pm 0.25^{* *}$ & $2.63 \pm 0.14^{* *}$ & $2.05 \pm 0.20^{* *}$ & $2.87 \pm 0.17^{* *}$ & $91.68 \pm 0.76$ & $63.40 \pm 1.64$ \\
\hline 15 & $6.17 \pm 0.40^{* *}+\dagger$ & $3.61 \pm 0.16^{* *}+\dagger$ & $2.08 \pm 0.10^{* *}$ & $3.05 \pm 0.11^{* *}+$ & $91.11 \pm 0.77$ & $63.17 \pm 1.51$ \\
\hline \multirow[t]{2}{*}{18} & $5.97 \pm 0.38^{* *}+$ & $3.72 \pm 0.20^{* *}+\dagger$ & $1.93 \pm 0.10^{* *} \dagger$ & $3.55 \pm 0.24^{* *}+\dagger$ & $88.03 \pm 1.46^{* *}+\dagger$ & $57.33 \pm 2.65^{* *}+\dagger$ \\
\hline & \multicolumn{6}{|c|}{ Diastolic function } \\
\hline Month(s) & $\mathrm{E} / \mathrm{A}$ & $\mathrm{E} / \mathrm{A} /$ & $\mathrm{E} / \mathrm{E} /$ & $\mathrm{DT}(\mathrm{ms})$ & \multicolumn{2}{|c|}{ IVRT(ms) } \\
\hline 1 & $2.85 \pm 0.20$ & $1.76 \pm 0.09$ & $19.23 \pm 3.05$ & $22.67 \pm 2.59$ & \multicolumn{2}{|l|}{$30.66 \pm 11.95$} \\
\hline 3 & $2.78 \pm 0.26$ & $1.72 \pm 0.09$ & $27.12 \pm 2.06^{* *}$ & $21.39 \pm 1.27$ & \multicolumn{2}{|l|}{$37.50 \pm 2.20$} \\
\hline 6 & $2.26 \pm 0.43^{*}$ & $0.56 \pm 0.05^{* *}$ & $29.66 \pm 3.64^{* *}$ & $26.67 \pm 4.77^{*}$ & \multicolumn{2}{|l|}{$39.14 \pm 6.54^{*}$} \\
\hline 9 & $2.15 \pm 0.34^{* *}$ & $0.63 \pm 0.07^{* *}$ & $31.65 \pm 3.00^{* *}$ & $24.41 \pm 2.55^{*}$ & \multicolumn{2}{|l|}{$37.22 \pm 13.07$} \\
\hline 12 & $2.19 \pm 0.32^{* *}$ & $0.55 \pm 0.09^{* *}$ & $35.36 \pm 4.29^{* *}$ & $24.17 \pm 4.02^{*}$ & \multicolumn{2}{|l|}{$38.75 \pm 4.54^{*}$} \\
\hline 15 & $2.06 \pm 0.09^{* *}+$ & $0.57 \pm 0.04^{* *}$ & $36.93 \pm 1.31^{* *}$ & $22.09 \pm 6.48$ & \multicolumn{2}{|l|}{$46.67 \pm 2.35^{* *}$} \\
\hline 18 & $1.98 \pm 0.23^{* *}+\dagger$ & $0.59 \pm 0.03^{* *}$ & $39.82 \pm 4.41^{* *}+\dagger$ & $26.33 \pm 3.31^{*}$ & \multicolumn{2}{|l|}{$40.17 \pm 7.60^{* *}$} \\
\hline
\end{tabular}

All data are means \pm SD. ${ }^{*} p<0.05$ vs. 1 month; ${ }^{* *} p<0.01$ vs. 1 month; $\dagger p<0.05$ vs. 12 month; †† $p<0.01$ vs. 12 month. 
Table 2 Serum concentrations of NT-proBNP, IL-6 and adiponectin in SHR

\begin{tabular}{|c|c|c|c|}
\hline $\begin{array}{l}\text { Month } \\
\text { (s) }\end{array}$ & $\begin{array}{l}\text { NT-proBNP } \\
\text { (fmol/ml) }\end{array}$ & $\begin{array}{c}\mathrm{IL}-6 \\
(\mathrm{pg} / \mathrm{ml})\end{array}$ & $\begin{array}{c}\text { Adiponectin } \\
\text { (ng/ml) }\end{array}$ \\
\hline 1 & $172.79 \pm 4.32$ & $13.24 \pm 1.25$ & $15.19 \pm 0.86$ \\
\hline 3 & $292.43 \pm 7.59^{* *}$ & $116.09 \pm 8.78^{* *}$ & $12.54 \pm 1.61^{*}$ \\
\hline 6 & $339.43 \pm 12.59^{* *}$ & $181.29 \pm 16.45^{* *}$ & $12.25 \pm 0.29^{*}$ \\
\hline 9 & $348.53 \pm 15.85^{* *}$ & $223.61 \pm 12.43^{* *}$ & $11.64 \pm 0.95^{*}$ \\
\hline 12 & $379.18 \pm 19.37^{* *}$ & $236.15 \pm 6.05 * *$ & $9.64 \pm 0.85^{* *}$ \\
\hline 15 & $386.52 \pm 19.69 * *$ & $260.05 \pm 9.90^{* *} \dagger$ & $10.45 \pm 1.52^{*} \dagger$ \\
\hline 18 & $\begin{array}{l}407.97 \pm 18.23 \\
* *+†\end{array}$ & $\begin{array}{l}421.45 \pm 19.49^{* *} \\
\text { t十 }\end{array}$ & $11.01 \pm 1.81^{*} \dagger$ \\
\hline
\end{tabular}

All data are means $\pm S D$. ${ }^{*} p<0.05$ vs. 1 month; ${ }^{* *} p<0.01$ vs. 1 month; $\dagger$ $p<0.05$ vs. 12 month; †† $p<0.01$ vs. 12 month.

\section{Results}

Body weight, systolic blood pressure and calculated left ventricular mass index

All rats survived. Body weight of SHR increased steadily with age and kept steady from 9 months to 18 months of age. There was significantly elevated SBP from $110 \pm 5 \mathrm{mmHg}$ at 1 month to $171 \pm 3 \mathrm{mmHg}$ at 3 months, and reached to $195 \pm 3 \mathrm{mmHg}$ at 6 months, henceforth remained plateau from 9 month to 18 month between $195 \pm 7 \mathrm{mmHg}$ and $190 \pm 9 \mathrm{mmHg}$. LVMI became greater and greater along with the development of hypertension and aging (Figure 1).

\section{Echocardiographic parameters}

Echocardiographic data are shown in Table 1. At 3 months of age, LV geometry of SHR demonstrated concentric hypertrophy associated with increased LVEDD, IVS and LVPW without change of LVESD. LVESD exhibited a steady increase at 9 months of age. Combined with progressively increased LVMI, an eccentric LV hypertrophy was overt. These observations are consistent with thickening of the walls between 3 and 18 months of age and a pattern of dilatation of the LV between 9 and 18 months of age.

To examine LV systolic function of SHR, echocardiographic measurements of left ventricular ejection fraction (EF) and fractional shorting (FS) were obtained. Compared with 1 month, both EF and FS declined at 18 months of age, or by $3.38 \%$ and $8.75 \%$, respectively, however, the decreases were both statistically significant.

Diastolic function was assessed by using Pulsed-Wave Doppler Imaging of mitral valve and Tissue Doppler Imaging of lateral mitral annulus. E/A ratio declined at 6 months of age, suggesting a trend toward a greater fraction of ventricular filling in late diastole. Of note, $E^{\prime} / A^{\prime}$ ratio decreased sharply at 6 months of age, and remained persistently below 1 during the rest period of study. E/E/ increased as early as at 3 months, which was in parallel with blood pressure elevation. There were trends of prolongation pertaining to IVRT and DT. Hence diastolic dysfunction occurs with establishment of hypertension and becomes apparent after 6 months of age.

\section{Serum adiponectin level inversely correlated with NT-proBNP and IL-6}

Serum NT-proBNP level was elevated from $172.79 \pm 4.32$ $\mathrm{fmol} / \mathrm{ml}$ at 1 month to $292.43 \pm 7.59 \mathrm{fmol} / \mathrm{ml}$ at 3 months and then fluctuated between $339.43 \pm 12.59 \mathrm{fmol} / \mathrm{ml}$ (6 months) and $407.97 \pm 18.23 \mathrm{fmol} / \mathrm{ml}$ (18 months). IL6 increased from $13.24 \pm 1.25 \mathrm{pg} / \mathrm{ml}$ (1 month) to $116.09 \pm 8.78 \mathrm{pg} / \mathrm{ml} \mathrm{(3} \mathrm{month)}$ and eventually to $421.45 \pm 19.49 \mathrm{pg} / \mathrm{ml}$ (18 month). However, adiponectin was initially decreased during first 3 months from $15.19 \pm 0.86 \mathrm{ng} / \mathrm{ml}$ (1 month) to $12.54 \pm 1.61 \mathrm{ng} / \mathrm{ml}$ (3 months) and then reached plateau until 15 months at $10.45 \pm 1.52 \mathrm{ng} / \mathrm{ml}$ compared to that of 12 months at

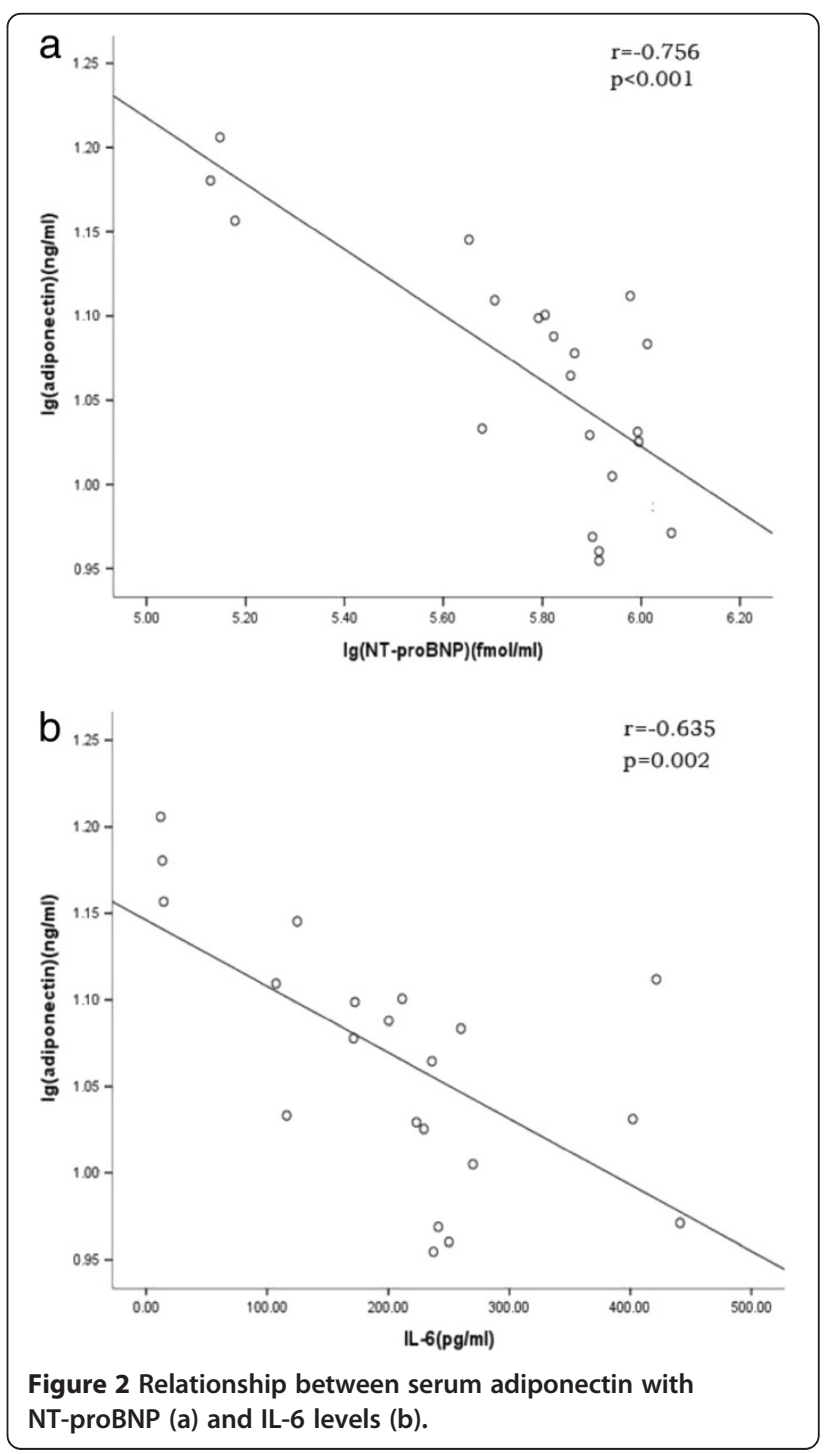


Table 3 Correlations of Ig(adiponectin) with echocardiographic diastolic indices

\begin{tabular}{llllcc}
\hline & E/A & E'/A' $^{\prime}$ & E/E' & DT(ms) & IVRT(ms) \\
\hline$r$ & 0.683 & 0.671 & -0.626 & 0.287 & -0.269 \\
\hline P value & 0.001 & 0.001 & 0.002 & 0.207 & 0.238 \\
\hline
\end{tabular}

$9.64 \pm 0.85 \mathrm{ng} / \mathrm{ml}$. As shown in Table 2 and Figure 2, significant negative correlation was observed between serum adiponectin and NT-proBNP levels $(r=-0.756$, $\mathrm{p}<0.001)$. And adiponectin level was also inversely correlated with IL-6 level $(r=-0.635, p=0.002)$.

\section{Correlations of serum adiponectin level with echocardiographic diastolic indices}

As shown in Table 3, correlation analysis demonstrated significant positive correlation between $\lg$ (adiponectin) and $\mathrm{E} / \mathrm{A}$ as well as $\mathrm{E}^{\prime} / \mathrm{A}^{\prime}$, while $\lg$ (adiponectin) was negatively correlated with $E / E^{\prime}$. There was no correlation between $\lg$ (adiponectin ) with DT and IVRT.

\section{Distribution \& expression of adiponectin and IL- 6}

There was no difference in distribution of adiponectin among pericardial, perinephric and mesenteric adipose tissues (Figure 3). However, with the development of left ventricular hypertrophy and cardiac dysfunction, adiponectin mRNA expression first decreased from 3 month to 12 month and then increased at 15 month thereafter (Figure 4). Meanwhile, IL-6 mRNA expression increased steadily with aging (Figure 5). Adiponectin and IL-6

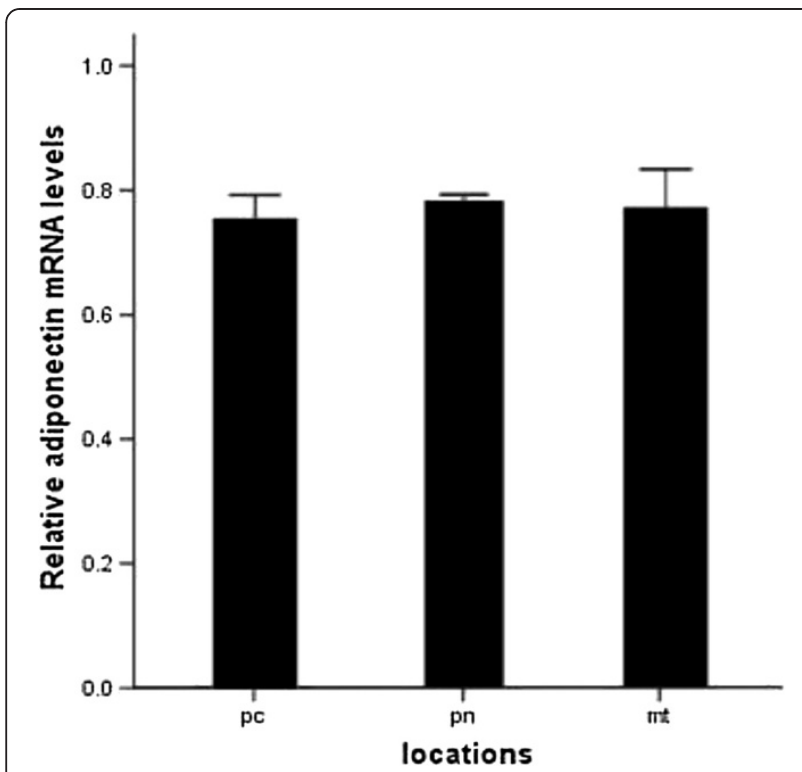

Figure 3 Quantitative RT-PCR analysis of adiponectin mRNA among three different locations. pc refers to pericardial adipose tissue; pn to perinephric adipose tissue; $m$ t to mesenteric adipose tissue. protein transcriptions were in line with mRNA expressions, respectively (Figure 6).

\section{Intraobserver reproducibility}

Reproducibility of the measurement of variables expressed as mean percent error was as follows: IVS, $1.44 \pm 2.25 \%$; EF, $5.83 \pm 2.81 \%$; FS, $6.19 \pm 4.80 \%$; E/A ratio, $0.66 \pm 1.61 \%$; E//A/ ratio, $0.46 \pm 1.26 \%$.

\section{Discussion}

The major findings of our study were that with advent of diastolic dysfunction since 3 month, adiponectin expression and serum concentration decreased simultaneously and increased at 15 month though systolic dysfunction appeared at 18 month. We also demonstrated no distribution differences of adiponectin among visceral adipose tissues.

SHR is a well established hypertension model similar to human hypertension such as the occurrence of LV hypertrophy followed by a transition to heart failure [17]. Therefore SHR has been regarded as a useful tool for studying the disease progression and mechanisms of LV hypertrophy and heart failure [18]. Echocardiography is one of the most widely used as a non-invasive technique to provide quantitative measurements of ventricular structure and function in humans and experimental animals. High-frequency transducers $(17.5 \mathrm{MHz})$ was used in our study, which greatly overcame the difficulties of a small weight of around $\sim 1 \mathrm{~g}$ with $2 \mathrm{~mm} \mathrm{LV}$ wall thickness in rats and a rapid heart rate of 300-400 bpm, providing high resolution images for morphometric and functional measurements $[19,20]$.

It is clear during the development of hypertension, alteration in LV geometry occurs as an early adaptation to increasing pressure and volume overload. In our study, during first 3 months, LVEDD, IVS and LVPW were increased whereas LVESD remain unchanged, indicating concentric hypertrophy. In the mean time cardiac function as assessed by echocardiography in terms of EF and FS was kept unchanged until 18 months. Meanwhile, diastolic dysfunction became overt from 6 month with decreased E/A ratio and $E^{\prime} / A^{\prime}$ ratio. However IVRT and DT values didn't alter possibly due to high heart rate [21].

As a key functional abnormality in diastolic dysfunction and heart failure, abnormal diastolic filling pressure leads to a release of natriuretic peptides including NTproBNP, which was released predominantly by the ventricles in response to stretch [22]. NT-proBNP levels increased significantly according to the severity of overall diastolic dysfunction, ranging from impaired relaxation to pseudonormal filling and restrictive filling, however, the role of NT-proBNP in patients with diastolic heart failure is still under investigation [23,24]. 


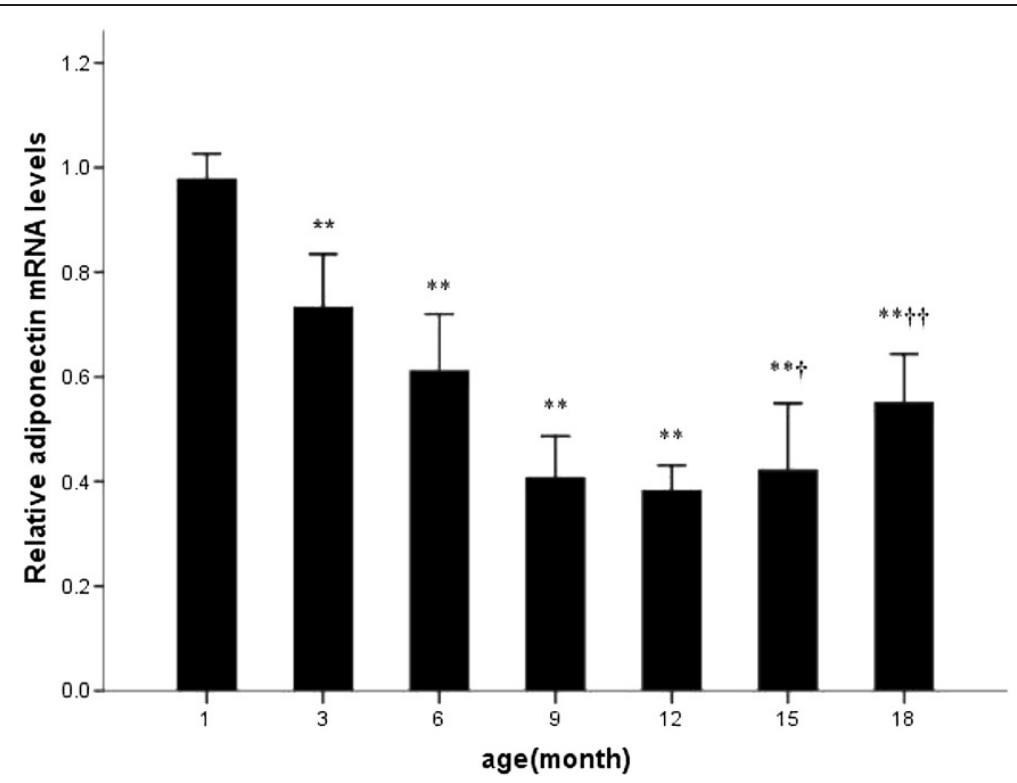

Figure 4 Quantitative RT-PCR analysis of adiponectin mRNA with disease progression. ${ }^{*} p<0.05$ vs. 1 month; ** $p<0.01$ vs. 1 month; $+p<0.05$ vs. 12 month; t† $p<0.01$ vs. 12 month.

Although it has been found that NT-proBNP correlates with diastolic abnormalities in patients with reduced systolic function [25] and in patients with advanced forms of isolated diastolic heart failure [26,27], several Doppler echocardiographic studies found them not to be useful for the detection of mild diastolic dysfunction. The latter is associated with increased filling pressures at exertion only and will be missed by conventional Doppler echocardiography, which is performed at rest.
Documented data indicated that chronic inflammation is closely associated with the development of cardiovascular and cardiovascular-related disorders, such as hypertension, heart failure, etc. Adipokines secreted from adipose tissue, such as leptin and interleukin-6 (IL-6) showed significant contribution to the positive regulation of inflammatory.

It is reported that low levels of adiponectin was associated with a further progression of left ventricular

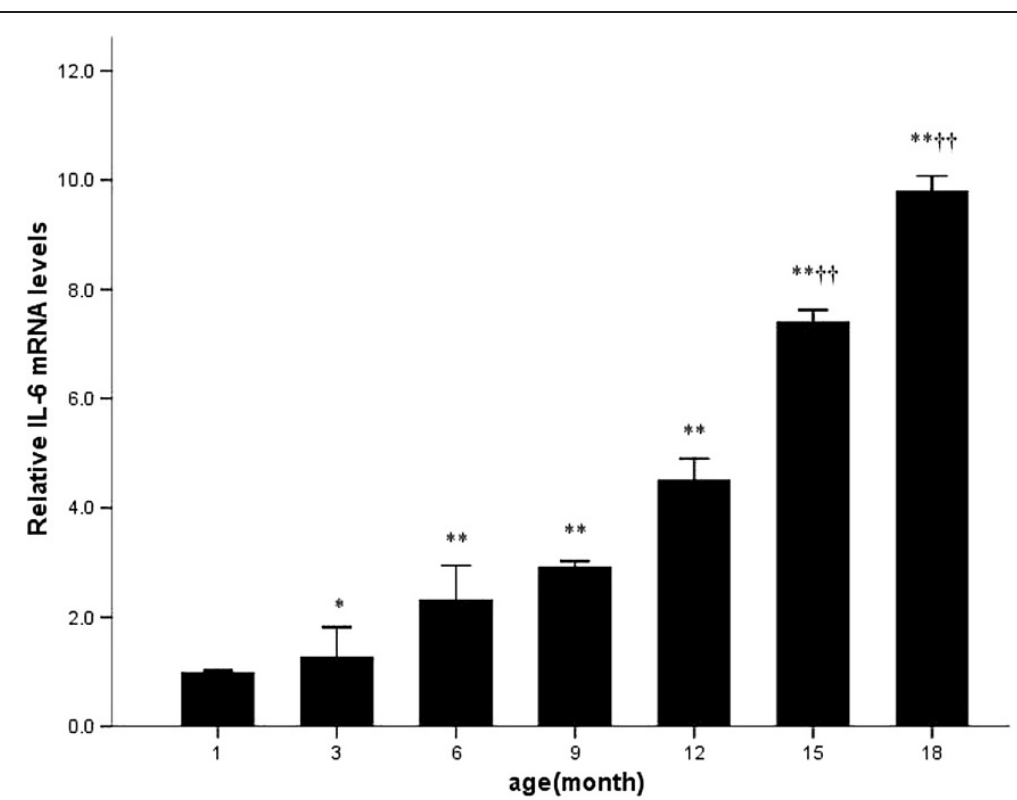

Figure 5 Quantitative RT-PCR analysis of IL-6 mRNA with disease progression. ${ }^{*} p<0.05$ vs. 1 month; ${ }^{* *} p<0.01$ vs. 1 month; t $p<0.05$ vs. 12 month; t† $p<0.01$ vs. 12 month. 
a

adiponectin

IL-6

$\beta$-actin

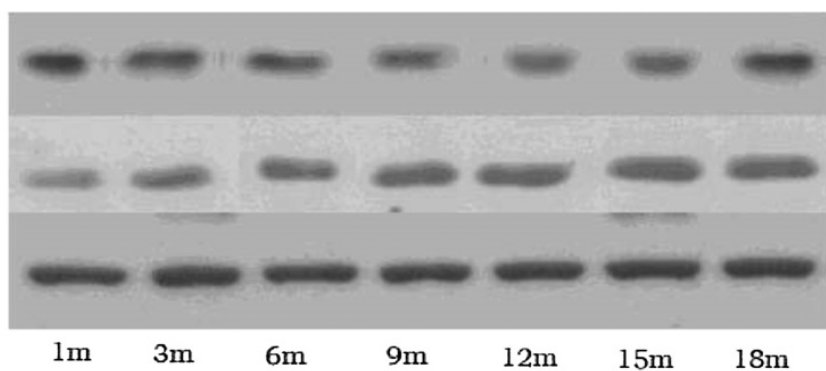

b
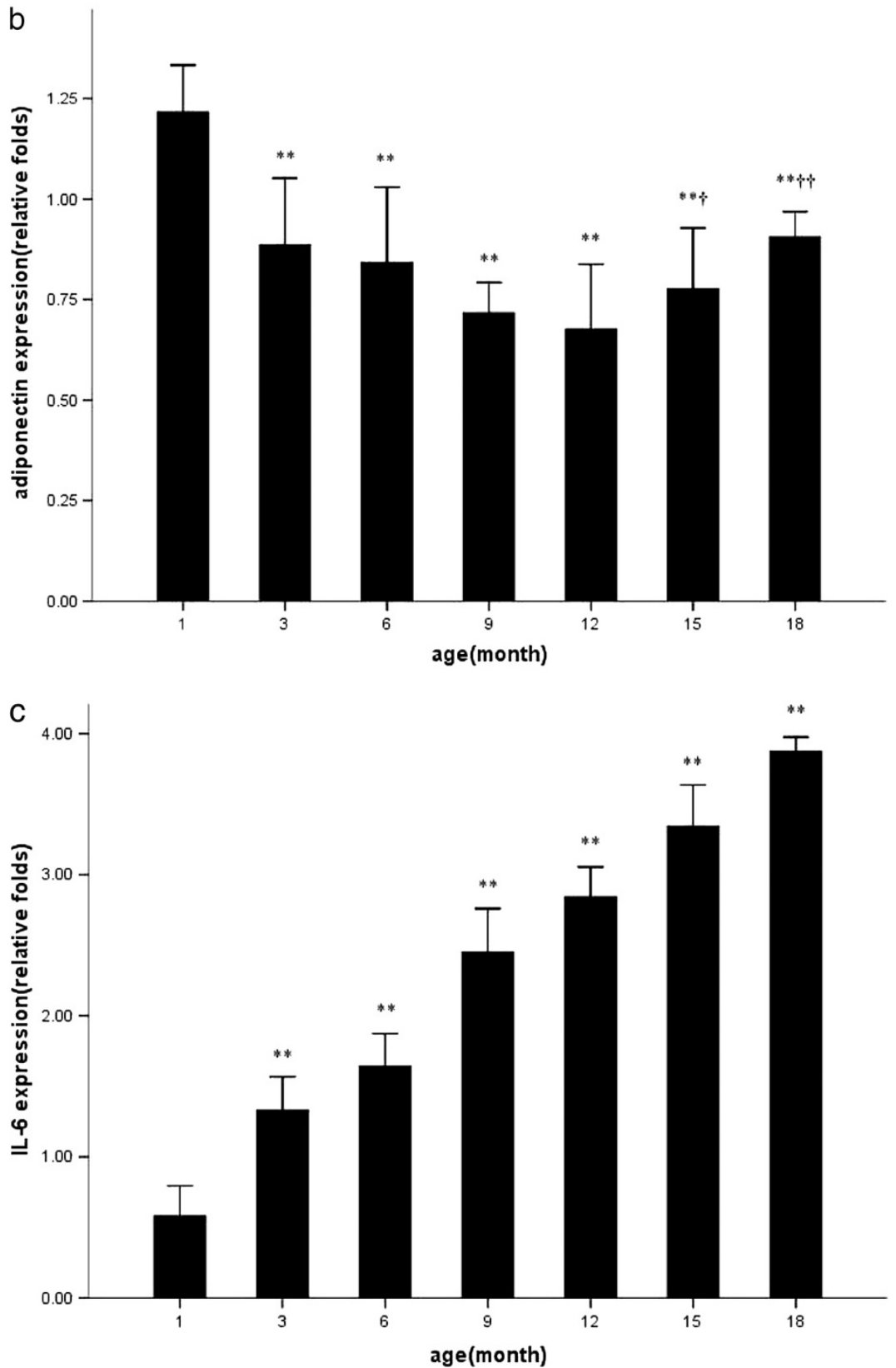

Figure 6 Representative western blots (a) and qualification of adiponectin and IL-6 protein expressions with disease progression (b, c). * $p<0.05$ vs. 1 month; ** $p<0.01$ vs. 1 month; $\dagger p<0.05$ vs. 12 month; $+\dagger p<0.01$ vs. 12 month. 
hypertrophy in patients presenting with hypertension, left ventricular diastolic dysfunction and hypertrophy [28]. Our data are in line with such reports describing an association between decreasing levels of adiponectin serum concentration and increasing hypertension. In current study we determined multiple biomarkers including NT-proBNP, IL-6 and adiponectin at multiple time points during transition period from hypertension to heart dysfunction. Reason for choosing a combination of biomarkers such as NT-proBNP, IL-6 and adiponectin is to cover different pathophysiological mechanisms such as cardiac stress, inflammation and adipocytokines. Our results have shown that, being different from NT-proBNP and IL-6 which keep increasing during progression of heart dysfunction, adiponectin was decreased from 3 month when diastolic dysfunction occurred and then increased at 15 month prior to advent of systolic dysfunction which was apparent at 18 month. Therefore adiponectin is the biomarker indicating onset rather than progression of heart dysfunction. In contrast, NT-proBNP and IL-6 are biomarkers not only for onset of heart dysfunction but also progression of heart dysfunction. Though our animal model is mainly hypertension induced heart dysfunction rather than heart failure, as is evidenced in other studies $[29,30]$, serum adiponectin level was elevated in chronic heart failure, our study also witnessed a trend.

Finally, adiponectin is produced exclusively by adipocytes [31] and its concentrations were predominantly determined by visceral fat [32]. However, up to now, difference in adiponectin gene expression in relation to various adipose tissue depots is still not fully elucidated [33]. Our study demonstrated no difference in adiponectin distribution, at least among pericardial, perinephric and mesenteric adipose tissues. However, adiponectin expression and serum level decreased with cardiac diastolic dysfunction and increased prior to systolic dysfunction while not in line with systolic dysfunction. We speculated the reasons might be as follows: (1) with disease progression, renal and hepatic functions might be impaired, and the clearance of adiponectin might also decrease [34,35], combined with relatively increased adiponectin expression, resulting in a prior serum elevation, which is partially consistent with our observations; (2) adiponectin is present in plasma in different isoforms: a large multimeric structure of high molecular weight and in a trimer and examer form, whereas the monomeric form is not found in peripheral circulation but only in the adipose tissue. Moreover, the lipolysis in adipose cells appears to be hormone-dependent, catecholamines and natriuretic peptides, besides insulin, exerting important effects [36]. (3) Circulating adiponectin concentrations can be regulated by various hormonal, nutritional and pharmacological factors. In heart dysfunction there are increased levels of IL-6 and
TNF- $\alpha$, as evidenced in our study, which might lead to decrease in serum adiponectin levels [37] and it is also reported adiponectin gene expression is reversibly downregulated by IL-6 [38]. The precise mechanism still needs further investigation.

In conclusion, we demonstrated that serum adiponectin level may be a useful biomarker during transition from hypertension to onset of cardiac dysfunction and adiponectin level is tempting to serve as a valuable indicator for early intervention. However, effectiveness and specificity are the two basic characteristics for a useful biomarker. The establishment of adiponectin as a valuable biomarker needs practical examination. Hence, whether and to what extent adiponectin could be used as a practical biomarker for cardiac function transition need more studies especially clinical data to support and prove and cautions should be take when making such conclusions.

\section{Competing interests}

The authors declare that they have no competing interests.

\section{Authors' contributions}

MF and JZ designed the study, carried out the experiments, and drafted the manuscript. JQ participated in the design of the study and helped to draft the manuscript. XJ performed the statistical analysis. $\mathrm{HZ}$ and $\mathrm{CZ}$ helped to carry out the experiments. MF participated in its design, and helped to draft the manuscript. YZ and JG revised the manuscript, conceived of the study, participated in its design. All authors read and approved the final manuscript.

\section{Acknowledgments}

We acknowledge funding supports from the National Basic Research Program of China (973 Program, 2012CB518605) and the National Natural Science Foundation of China (81070105). The authors express their appreciation to Jia Jianguo for operation of SHR echocardiography.

\section{Author details}

${ }^{1}$ Shanghai Institute of Cardiovascular Diseases, Department of Cardiology, Zhongshan Hospital, Fudan University, Shanghai, China. ${ }^{2}$ Department of Medicine, Sahlgrenska University Hospital/Sahlgrenska, Gothenburg, Sweden. ${ }^{3}$ Institutes of Biomedical Sciences, Fudan University, Shanghai, China.

Received: 15 May 2012 Accepted: 12 August 2012

Published: 30 August 2012

\section{References}

1. Ikeoka D, Mader JK, Pieber TR: Adipose tissue, inflammation and cardiovascular disease. Rev Assoc Med Bras 2010, 56:116-121.

2. Yang Q, Graham TE, Mody N, Preitner F, Peroni OD, Zabolotny JM, Kotani K, Quadro L, Kahn BB: Serum retinol binding protein 4 contributes to insulin resistance in obesity and type 2 diabetes. Nature 2005, 436:356-362.

3. Calabro P, Yeh ET: Obesity, inflammation, and vascular disease: the role of the adipose tissue as an endocrine organ. Subcell Biochem 2007, 42:63-91.

4. Scherer PE: Adipose tissue: from lipid storage compartment to endocrine organ. Diabetes 2006, 55:1537-1545.

5. Arita Y, Kihara S, Ouchi N, Takahashi M, Maeda K, Miyagawa J, Hotta K, Shimomura I, Nakamura T, Miyaoka K, Kuriyama H, Nishida M, Yamashita S, Okubo K, Matsubara K, Muraguchi M, Ohmoto Y, Funahashi T, Matsuzawa Y: Paradoxical decrease of an adipose-specific protein, adiponectin, in obesity. Biochem Biophys Res Commun 1999, 257:79-83.

6. Maeda K, Okubo K, Shimomura I, Funahashi T, Matsuzawa Y, Matsubara K: cDNA cloning and expression of a novel adipose specific collagen-like factor, apM1 (AdiPose Most abundant Gene transcript 1). Biochem Biophys Res Commun 1996, 221:286-289.

7. Mao X, Hong JY, Dong LQ: The adiponectin signaling pathway as a novel pharmacological target. Mini Rev Med Chem 2006, 6:1331-1340. 
8. Shibata R, Ouchi N, Ito M, Kihara S, Shiojima I, Pimentel DR, Kumada M, Sato K, Schiekofer S, Ohashi K, Funahashi T, Colucci WS, Walsh K: Adiponectinmediated modulation of hypertrophic signals in the heart. Nat Med 2004, 10:1384-1389.

9. Maeda N, Shimomura I, Kishida K, Nishizawa H, Matsuda M, Nagaretani H, Furuyama N, Kondo H, Takahashi M, Arita Y, Komuro R, Ouchi N, Kihara S, Tochino Y, Okutomi K, Horie M, Takeda S, Aoyama T, Funahashi T, Matsuzawa Y: Diet-induced insulin resistance in mice lacking adiponectin/ACRP30. Nat Med 2002, 8:731-737.

10. Kadowaki T, Yamauchi T: Adiponectin and adiponectin receptors. Endocr Rev 2005, 26:439-451.

11. Szmitko PE, Teoh H, Stewart DJ, Verma S: Adiponectin and cardiovascular disease: state of the art? Am J Physiol Heart Circ Physiol 2007, 292:H1655-H1663.

12. Ran J, Hirano T, Fukui T, Saito K, Kageyama H, Okada K, Adachi M: Angiotensin II infusion decreases plasma adiponectin level via its type 1 receptor in rats: an implication for hypertension-related insulin resistance. Metabolism 2006, 55:478-488.

13. Imatoh T, Miyazaki M, Momose $\mathrm{Y}$, Tanihara S, Une H: Adiponectin levels associated with the development of hypertension: a prospective study. Hypertens Res 2008, 31:229-233.

14. Chow WS, Cheung BM, Tso AW, Xu A, Wat NM, Fong CH, Ong LH, Tam S, Tan KC, Janus ED, Lam TH, Lam KS: Hypoadiponectinemia as a predictor for the development of hypertension: a 5-year prospective study. Hypertension 2007, 49:1455-1461.

15. Sahn DJ, DeMaria A, Kisslo J, Weyman A: Recommendations regarding quantitation in M-mode echocardiography: results of a survey of echocardiographic measurements. Circulation 1978, 58:1072-1083.

16. Maron BJ, Spirito P, Green KJ, Wesley YE, Bonow RO, Arce J: Noninvasive assessment of left ventricular diastolic function by pulsed Doppler echocardiography in patients with hypertrophic cardiomyopathy. J Am Coll Cardiol 1987, 10:733-742

17. Trippodo NC, Frohlich ED: Similarities of genetic (spontaneous) hypertension. Man and rat. Circ Res 1981, 48:309-319.

18. Boluyt MO, Bing OH, Lakatta EG: The ageing spontaneously hypertensive rat as a model of the transition from stable compensated hypertrophy to heart failure. Eur Heart J 1995, 16:19-30.

19. de Simone G, Wallerson DC, Volpe M, Devereux RB: Echocardiographic measurement of left ventricular mass and volume in normotensive and hypertensive rats. Necropsy validation. Am J Hypertens 1990, 3:688-696.

20. Tanaka N, Dalton N, Mao L, Rockman HA, Peterson KL, Gottshall KR, Hunter $\mathrm{JJ}$, Chien KR, Ross J Jr: Transthoracic echocardiography in models of cardiac disease in the mouse. Circulation 1996, 94:1109-1117.

21. Schaefer A, Meyer GP, Brand B, Hilfiker-Kleiner D, Drexler H, Klein G: Effects of anesthesia on diastolic function in mice assessed by echocardiography. Echocardiography 2005, 22:665-670.

22. Brutsaert DL: Diagnosing primary diastolic heart failure. Eur Heart J 2000, 21:94-96.

23. Yamaguchi H, Yoshida J, Yamamoto K, Sakata Y, Mano T, Akehi N, Hori M, Lim YJ, Mishima M, Masuyama T: Elevation of plasma brain natriuretic peptide is a hallmark of diastolic heart failure independent of ventricular hypertrophy. J Am Coll Cardiol 2004, 43:55-60.

24. Maisel AS, McCord J, Nowak RM, Hollander JE, Wu AH, Duc P, Omland T, Storrow AB, Krishnaswamy P, Abraham WT, Clopton P, Steg G, Aumont MC, Westheim A, Knudsen CW, Perez A, Kamin R, Kazanegra R, Herrmann HC, McCullough PA, Breathing Not Properly Multinational Study Investigators: Bedside B-Type natriuretic peptide in the emergency diagnosis of heart failure with reduced or preserved ejection fraction. Results from the Breathing Not Properly Multinational Study. J Am Coll Cardiol 2003, 41:2010-2017

25. Troughton RW, Prior DL, Pereira JJ, Martin M, Fogarty A, Morehead A Yandle TG, Richards AM, Starling RC, Young JB, Thomas JD, Klein AL: Plasma B-type natriuretic peptide levels in systolic heart failure: importance of left ventricular diastolic function and right ventricular systolic function. J Am Coll Cardiol 2004, 43:416-422.

26. Mottram PM, Leano R, Marwick TH: Usefulness of B-type natriuretic peptide in hypertensive patients with exertional dyspnea and normal left ventricular ejection fraction and correlation with new echocardiographic indexes of systolic and diastolic function. Am J Cardiol 2003, 92:1434-1438
27. Alehagen $U$, Lindstedt $G$, Levin LA, Dahlström U: The risk of cardiovascular death in elderly patients with possible heart failure. Results from a 6year follow-up of a Swedish primary care population. Int J Cardiol 2005, 100:17-27.

28. Hong SJ, Park CG, Seo HS, Oh DJ, Ro YM: Associations among plasma adiponectin, hypertension, left ventricular diastolic function and left ventricular mass index. Blood Press 2004, 13:236-242.

29. George J, Patal S, Wexler D, Sharabi Y, Peleg E, Kamari Y, Grossman E, Sheps $D$, Keren $G$, Roth A: Circulating adiponectin concentrations in patients with congestive heart failure. Heart 2006, 92:1420-1424.

30. Oztürk M, Dursunoğlu D, Göksoy H, Rota S, Gür S: Evaluation of serum adiponectin levels in patients with heart failure and relationship with functional capacity. Turk Kardiyol Dern Ars 2009, 37:384-390.

31. Scherer PE, Williams S, Fogliano M, Baldini G, Lodish HF: A novel serum protein similar to $\mathrm{C} 1 \mathrm{q}$, produced exclusively in adipocytes. $J \mathrm{Bio} / \mathrm{Chem}$ 1995, 270:26746-26749.

32. Staiger $\mathrm{H}$, Tschritter $\mathrm{O}$, Machann J, Thamer C, Fritsche A, Maerker E, Schick F, Häring HU, Stumvoll M: Relationship of serum adiponectin and leptin concentrations with body fat distribution in humans. Obes Res 2003, 11:368-372.

33. Fisher FM, McTernan PG, Valsamakis G, Chetty R, Harte AL, Anwar AJ, Starcynski J, Crocker J, Barnett AH, McTernan CL, Kumar S: Differences in adiponectin protein expression: effect of fat depots and type 2 diabetic status. Horm Metab Res 2002, 34:650-654.

34. Zoccali C, Mallamaci F, Tripepi G, Benedetto FA, Cutrupi S, Parlongo S, Malatino LS, Bonanno G, Seminara G, Rapisarda F, Fatuzzo P, Buemi M, Nicocia G, Tanaka S, Ouchi N, Kihara S, Funahashi T, Matsuzawa Y: Adiponectin, metabolic risk factors, and cardiovascular events among patients with end-stage renal disease. J Am Soc Nephrol 2002, 13:134-141.

35. Tietge UJ, Böker KH, Manns MP, Bahr MJ: Elevated circulating adiponectin levels in liver cirrhosis are associated with reduced liver function and altered hepatic hemodynamics. Am J Physiol Endocrinol Metab 2004, 287:E82-E89.

36. Arner P: Human fat cell lipolysis: biochemistry, regulation and clinical role. Best Pract Res Clin Endocrinol Metab 2005, 19:471-482.

37. Nishida M, Funahashi T, Shimomura I: Pathophysiological significance of adiponectin. Med Mol Morphol 2007, 40:55-67.

38. Skurk T, Alberti-Huber C, Herder C, Hauner H: Relationship between adipocyte size and adipokine expression and secretion. J Clin Endocrinol Metab 2007, 92:1023-1033.

doi:10.1186/1476-511X-11-106

Cite this article as: Fu et al:: Adiponectin through its biphasic serum level is a useful biomarker during transition from diastolic dysfunction to systolic dysfunction - an experimental study. Lipids in Health and Disease 2012 11:106.

\section{Submit your next manuscript to BioMed Central and take full advantage of:}

- Convenient online submission

- Thorough peer review

- No space constraints or color figure charges

- Immediate publication on acceptance

- Inclusion in PubMed, CAS, Scopus and Google Scholar

- Research which is freely available for redistribution 